\title{
GERAÇÃO Y E O EMPREGO IDEAL: PERCEPÇÃO DOS ESTUDANTES \\ DE UM CENTRO UNIVERSITÁRIO
}

\author{
Y GENERATION AND IDEAL JOB: STUDENTS PERCEPTION \\ OF A UNIVERSITY CENTER
}

\section{GENERACIÓN Y Y EL EMPLEO IDEAL: PERCEPCIÓN DE LOS ESTUDIANTES DE UN CENTRO UNIVERSITARIO}

Recebimento: 29/01/2018- Aceite: 13/10/2018- Publicação: 28/10/2018

Processo de Avaliação: Double Blind Review

Silvia Regina Guberovic ${ }^{1}$

Mestre em Administração em Governança Corporativa

Centro Universitário Eniac

srguberovic@gmail.com

Adams Gabriel Moraes

Graduado em Administração

adams.moraes@gmail.com

Sergio Roberto da Silva

Doutorando em Administração

Centro universitário das Faculdades de Engenharia Industrial-FEI-SP

admsrsmsc@gmail.com

Valéria Guedes Caruso

Mestre em Educação

Centro Universitário Eniac

valeria.guedes@eniac.edu.br

\section{RESUMO}

A multiplicidade de comportamentos que são próprias dos seres humanos, quando avaliadas nos contextos organizacionais, oferece a oportunidade de observar como as relações dos grupos geracionais são estabelecidas e a sua percepção sobre o emprego. Em um processo

\footnotetext{
${ }^{1}$ Autor para correspondência: Centro Universitário ENIAC: R. Força Pública, 89 - Centro, Guarulhos - SP, Brasil. CEP: 07012-030.
} 
natural de evolução, o comportamento das pessoas se modifica e, consequentemente, as empresas precisam atender tanto as demandas de mercado como as de seus profissionais, com visões e valores diferenciados entre as gerações. Considerando este cenário, a pesquisa teve por objetivo identificar a percepção dos estudantes de um centro universitário pertencentes à Geração Y sobre o emprego ideal. A metodologia utilizada foi um survey aplicado aos estudantes universitários de um Centro Universitário do município de Guarulhos. O instrumento teve origem em Berthon et al. (2005), com 25 itens classificados em cinco dimensões: rotina de trabalho, interação pessoal, benefícios econômicos, desenvolvimento profissional e responsabilidade social. A escala apresentou-se em formato tipo Likert de sete pontos, variando de 1: discordo totalmente a 7: concordo totalmente. Os resultados apontam que os profissionais da Geração Y gostam de trabalhar em empresas que aplicam novas práticas de trabalho e consideram importante o bom relacionamento com a chefia e colegas.

Palavras-Chave: Geração Y. Emprego ideal. Comportamento organizacional.

\begin{abstract}
The multiplicity of behaviors that are proper for human beings, when evaluated in organizational contexts, provides the opportunity to observe how the relations of generational groups are established and their perception about employment. In a natural process of evolution, people's behavior changes and, consequently, companies need to meet both the market demands and the demands of their professionals, with differentiated views and values amongst generations. Considering this scenario the research had the objective to identify the perception of the students of a University Center belonging to the Y Generation on the ideal job. The methodology used was a survey applied to university students of a University Center in the city of Guarulhos. The instrument was originated from Berthon et al. (2005), with 25 items classified in five dimensions: work routine, personal interaction, economic benefits, professional development and social responsibility. The scale was presented in a seven-point Likert format, ranging from 1: totally disagree, to 7: I totally agree. The results show that $Y$ Generation professionals like to work in companies that apply new work practices; they consider important to have a good relationship with the boss and colleagues.
\end{abstract}

Keywords: Y Generation. Ideal job. Organizational behavior.

\title{
RESUMEN
}

La multiplicidad de comportamientos que son propios de los seres humanos, cuando se evalúan en los contextos organizacionales, ofrece la oportunidad de observar cómo se establecen las relaciones de los grupos generacionales y su percepción sobre el empleo. En un proceso natural de evolución, el comportamiento de las personas se modifica y consecuentemente, las empresas necesitan atender tanto las demandas de mercado como la de sus profesionales, con visiones y valores diferenciados entre las generaciones. Considerando este escenario la investigación tuvo por objetivo identificar la percepción de los estudiantes de un centro universitario pertenecientes a la Generación Y sobre el empleo ideal. La metodología utilizada fue un survey aplicado a los estudiantes universitarios de un Centro Universitario del municipio de Guarulhos. El instrumento se originó en Berthon et al. (2005), con 25 ítems 
clasificados en cinco dimensiones: rutina de trabajo, interacción personal, beneficios económicos, desarrollo profesional y responsabilidad social. La escala se presentó en formato tipo Likert de siete puntos, variando de 1: discordo totalmente, a 7: estoy totalmente de acuerdo. Los resultados apuntan que los profesionales de la Generación Y les gusta trabajar en empresas que aplican nuevas prácticas de trabajo; consideran importante la buena relación con la jefatura y colegas.

\section{Palabras Clave: Generación Y. Empleo ideal. Comportamiento organizacional.}

\section{INTRODUÇÃO}

Mudanças econômicas, políticas, sociais e tecnológicas compõem o cenário das organizações assim como o comportamento das pessoas se modifica ao longo do tempo. Entende-se que faz parte do processo natural de evolução. Em termos profissionais, tais fatores levam as empresas a adotarem práticas que atendam as demandas do mercado e das pessoas que ocupam os postos de trabalho nas organizações.

Em relação aos profissionais e o comportamento nas organizações, Robbins (2009, p.2) destaca que "refere-se ao estudo sistemático das ações e atitudes que as pessoas apresentam dentro das organizações." Assim, o comportamento impacta no relacionamento entre as pessoas que compõem a organização.

Adami (2014, p.49) destaca que em um mesmo ambiente de trabalho convivem pessoas com expectativas diferentes sobre trabalho, carreira dentre outros. Estas diferentes pessoas podem ser classificadas em gerações e denominadas: baby boomers, geração X, geração Y e a geração Z.

A geração Y, foco do estudo, apresenta visão e valores diferenciados no que diz respeito à sua relação com o trabalho, buscando o significado de seu trabalho, com senso de imediatismo, inovação e integração tecnológica.

De acordo com Oliveira (2011, p. 38), “o grande legado do jovem, seu supremo reconhecimento, não acontecerá por uma carreira profissional, mas por sua carreira de vida". Essa geração prima pela qualidade de vida, sendo o trabalho um elemento de satisfação para a sua vida; portanto, tanto o lado pessoal como profissional estão interligados, ao contrário de antigamente que havia dicotomia entre vida pessoal e profissional.

Com base no exposto, o trabalho buscou investigar: Qual a percepção da Geração Y sobre o emprego ideal? 
Assim, a presente pesquisa objetivou identificar qual é a percepção dos estudantes de um centro universitário pertencentes à Geração Y sobre o emprego ideal.

O estudo se faz necessário para demonstrar o que essa geração pensa e espera sobre o trabalho. O Estudo é útil às organizações na sua gestão de Pessoas criando estratégias para reter esse publico. Academicamente o estudo contribui com a pesquisa nessa cidade da grande São Paulo e com a junção de mais bibliografia sobre o assunto.

Este trabalho está organizado em introdução, referencial, metodologia de pesquisa, discussão dos resultados e por fim as considerações finais.

\section{REFERENCIAL TEÓRICO}

A sociedade é formada por pessoas e uma das formas de organizá-la é a divisão por gerações de acordo com a similaridade de faixa etária. As diferenciações se apresentam também quanto ao conhecimento, habilidades e atitudes, sendo estas mais evidenciadas no âmbito profissional.

De acordo com Adami (2014, p.49) 'no mundo corporativo, são encontradas três faixas de gerações: baby boomers, geração X e geração Y'. Percebe-se que o modo de fazer as coisas está mudando de maneira rápida e o intervalo entre uma geração e outra ficou mais curto, fazendo com que várias gerações estejam convivendo no mesmo ambiente de trabalho.

Segundo Adami (2014), a geração baby boomers surgiu entre 1945 e 1960, logo após a Segunda Guerra Mundial. Seus objetivos eram a prosperidade e a paz, construíram carreiras e ainda hoje permanecem na empresa com altos cargos e suas características são a lealdade, disciplina e respeito à autoridade. Logo após surgiu a geração X, no começo de 1960.

Ainda de acordo com a autora, a geração $X$ vivenciou períodos de transformações. Quando a tecnologia começou fazer parte na vida dessas pessoas, tiveram de se adaptar às mudanças. Começaram a investir mais na qualidade de carreira e conquistas pessoais. Já a geração Y, nascidos a partir de 1983, é conhecida como geração do milênio ou digital.

A geração $Z$ que entra no mercado de trabalho recentemente, conforme Oliveira (2011) são os nascidos a partir de 2000, caracterizados por serem conectados e relacionais.

A geração $\mathrm{Y}$, foco da pesquisa, é caracterizada por ser otimista disposta a aprender, inovar, valorizar a diversidade e integrada tecnologicamente, assim tem facilidade em usar a tecnologia a seu favor, comparado às gerações anteriores. 
Não há dúvida de que os recursos tecnológicos são os grandes viabilizadores dessa capacidade de realizar múltiplas tarefas ao mesmo tempo. Porém, cientes de que os recursos estão à disposição de todos, sabemos também que a intimidade com tais meios é atributo de poucos, dentre eles o grupo inteiro dos ípsilons. (CALLIARI; MOTTA, 2012, p. 10)

Para que o trabalho seja produtivo, é preciso lidar com o conflito entre as gerações. Oliveira (2011, p. 25) relata que "o ambiente corporativo tornou-se extremamente complexo e os modelos de gestão de pessoal que permitiam o desenvolvimento de jovens profissionais sofreram profunda alteração".

Considerando que cada geração tem seus valores pessoais e profissionais peculiares, Robbins, Judge e Sobral (2010, p. 141) afirmam que os valores na força de trabalho para a geração Y são "autoconfiança, sucesso financeiro, independência pessoal, junto com trabalho de equipe, lealdade a si mesmos e aos relacionamentos”. É uma geração que também busca soluções rápidas e fáceis para os problemas.

Para que os gestores saibam lidar com as diferenças entre as gerações, é necessário entender e respeitar as diferenças de valores e pontos de vista, estando dispostos às mudanças e à troca de conhecimento que uma geração pode agregar à outra, trazendo benefícios para a organização.

É importante ressaltar que para um bom convívio e produtividade, a organização tenha sua cultura e seus valores bem definidos, gerindo assim a diversidade.

De acordo com Dessler (2014) gerir a diversidade é tornar os funcionários mais sensíveis e capazes de se adaptarem às diferenças culturais individuais, propiciando o desenvolvimento, utilizando as competências em uma mistura de talentos e percepções como fonte de vantagem competitiva para a organização. Deste modo, estará proporcionando um ambiente de trabalho que atenda às necessidades de cada geração, com um bom clima organizacional, interatividade, liberdade de comunicação, criatividade e recursos tecnológicos.

Outro aspecto importante a ser destacado refere-se à remuneração variável como fator chamariz para esta geração. Calliari e Motta (2012) relatam que benefícios, recompensas e outras maneiras de premiar suas atuações são muito bem-vindas e apreciadas, condizentes a sua perspectiva de justiça em merecer por aquilo que se faz.

Sobre remuneração estratégica, Orsi (2015) relata que a base da remuneração por competências está na verificação do grau em que a pessoa atende às demandas do contexto no 
qual atua, considerando a complexidade e responsabilidade em que está posicionada. Dessa forma, seu comprometimento será maior.

Assim, é imprescindível que haja motivação e que a organização possa retê-los, mostrando novas perspectivas de futuro, plano de carreira, que possa propiciar também seu empoderamento, estimulando sua estima e comprometimento com o trabalho, pois esta não é uma geração que se preocupa com a estabilidade, mas que está sempre procurando o significado de seu trabalho.

Além de seu desenvolvimento profissional, essa geração se preocupa com a responsabilidade social no ambiente em que trabalham. De acordo com Adami (2014, p.51) "a geração Y busca nas organizações aquilo que ele valoriza, ou seja, organizações que se preocupem com filantropia, sustentabilidade e com trabalhos voluntários”.

No entanto, há uma nova percepção de emprego ideal para a geração Y.

Pode-se afirmar que a vida profissional invadiu a vida pessoal. Como consequência, a expectativa dos profissionais também mudou e agora busca refletir a possibilidade de equilibrar o trabalho com as demais dimensões pessoais dando total importância à qualidade de vida. (OLIVEIRA, 2011, p. 30)

A vida pessoal e do trabalho tem se tornado uma tarefa cada vez mais difícil com a diminuição de postos de trabalho, aumento das exigências sobre o trabalhador, avanço das telecomunicações que tornam o trabalho presente em qualquer lugar e expectativas quanto à qualidade de vida.

Considerando que uma das características da Geração Y é o aspecto tecnológico, a pesquisa buscou verificar, por meio das hipóteses, o fator relacionamento interpessoal e levantou duas hipóteses. A primeira, é que a Geração Y não considera importante os relacionamentos interpessoais estabelecidos com as chefias e colegas, e a segunda hipótese levantada, é que a Geração Y considera importante os relacionamentos interpessoais estabelecidos com as chefias e colegas.

\section{METODOLOGIA}

Este tópico tem por objetivo apresentar os procedimentos metodológicos da pesquisa.

O trabalho foi classificado como exploratório, já que significa um estudo sobre a Geração Y em relação ao emprego ideal, na percepção dos estudantes universitários de um Centro Universitário da cidade de Guarulhos. 
De acordo com Severino (2007, p. 123), “a pesquisa exploratória busca apenas levantar informações sobre um determinado objeto, delimitando assim um campo de trabalho, mapeando as condições de manifestação desse objeto".

A pesquisa foi de natureza quantitativa. Segundo Mascarenhas (2012, p. 45): "a pesquisa quantitativa baseia-se na quantificação para coletar e, mais tarde, tratar os dados obtidos". O método de análise dos dados coletados escolhido foi o de estatística descritiva.

O desenvolvimento do tema foi realizado por meio de pesquisa bibliográfica para dar sustentação teórica o entendimento, análise e discussão dos resultados. De acordo com Gil (2008, p.50):

\footnotetext{
A pesquisa bibliográfica é desenvolvida a partir de material já elaborado, constituído principalmente de livros e artigos científicos. Embora em quase todos os estudos seja exigido algum tipo de trabalho desta natureza, há pesquisas desenvolvidas exclusivamente a partir de fontes bibliográficas.
}

Os sujeitos dessa pesquisa foram estudantes universitários de um Centro Universitário do município de Guarulhos. A pesquisa foi do tipo survey. A pesquisa foi realizada com 197 estudantes e chegou-se a um total de 70 entrevistados da Geração Y, que conforme Oliveira (2011) são os nascidos no período compreendido entre 1983 e 1994.

O questionário apresentou duas partes. A primeira composta por dados sociodemográficos e a segunda parte com o instrumento de pesquisa científica. $\mathrm{O}$ instrumento de pesquisa utilizado foi a escala de Berthon et al. (2005), com 25 itens classificados em cinco dimensões: rotina de trabalho, interação pessoal, benefícios econômicos, desenvolvimento profissional e responsabilidade social. A escala apresenta-se em formato tipo Likert de sete pontos, variando de 1: discordo totalmente, a 7: concordo totalmente.

Como procedimento para coleta dos dados, o questionário da pesquisa foi desenvolvido on-line, por meio do survey monkey. As pessoas foram convidadas verbalmente para preencherem o questionário. Em seguida, esses assinavam o termo de livre consentimento (TLC) da pesquisa. Foram aplicados, também, questionários em formulário e os resultados digitados no software survey monkey.

\section{APRESENTAÇÃO E ANÁLISE DOS RESULTADOS}

O objetivo desta pesquisa é apresentar as análises realizadas a partir dos dados coletados. 


\subsection{Caracterização da amostra estudada - Aspectos sociodemográficos}

Tabela 1 - Faixa Etária.

\begin{tabular}{lcl}
\hline Variáveis & Frequência & Percentual \\
\hline Idade & 16 & 22,9 \\
23 & 2 & 2,9 \\
24 & 4 & 5,7 \\
25 & 5 & 7,1 \\
26 & 4 & 5,7 \\
27 & 2 & 2,9 \\
28 & 9 & 12,9 \\
29 & 14 & 20 \\
30 & 5 & 7,1 \\
31 & 4 & 5,7 \\
32 & 4 & 5,7 \\
33 & 1 & 1,4 \\
34 & & \\
Total & $\mathbf{7 0}$ & $\mathbf{1 0 0} \%$ \\
\hline
\end{tabular}

Fonte: Dados da pesquisa (2017).

Com relação à faixa etária, a maior concentração dos respondentes está na que se refere a 23 anos, com 16 pessoas, correspondendo a 22,9\% da amostra. Em seguida, observa-se que a faixa etária de 30 anos concentra 14 respondentes, correspondendo a 20\% da amostra.

Tabela 2 - Gênero.

\begin{tabular}{lcc}
\hline Gênero & Frequência & Percentual \\
\hline feminino & 51 & 72,9 \\
Masculino & 19 & 27,1 \\
\hline Total & $\mathbf{7 0}$ & $\mathbf{1 0 0 \%}$ \\
\hline
\end{tabular}

Fonte: Dados da pesquisa (2017)

Quanto ao gênero, o maior número de respondentes é do gênero feminino correspondendo a $72,9 \%$ e $27,1 \%$ do gênero masculino, evidenciando a prevalência do gênero feminino na pesquisa. 
Tabela 3 - Estado Civil

\begin{tabular}{lcc}
\hline Variáveis & Frequência & Percentual \\
\hline Solteiro (a) & 46 & 65,7 \\
Casado (a) & 21 & 30 \\
Separado (a) & 1 & 1,4 \\
Divorciado (a) & 2 & 2,9 \\
\hline Total & $\mathbf{7 0}$ & $\mathbf{1 0 0} \%$ \\
\hline
\end{tabular}

Fonte: Dados da pesquisa (2017).

$\mathrm{Na}$ análise do Estado Civil, verifica-se maior frequência de solteiros(as), correspondendo a $65,7 \%$ e $30 \%$ casados (as). Os demais percentuais distribuem-se entre separado (a) e divorciado (a).

Tabela 4 - Vínculo empregatício.

\begin{tabular}{lcc}
\hline Variáveis & Frequência & Percentual \\
\hline Atualmente você está & & \\
Desempregado & 9 & 12,9 \\
Trabalhando & 60 & 85,7 \\
Nunca trabalhei ou estagiei & 1 & 1,4 \\
\hline Total & $\mathbf{7 0}$ & $\mathbf{1 0 0 \%}$ \\
\hline
\end{tabular}

Fonte: Dados da pesquisa (2017).

Com relação ao vínculo empregatício, verificou-se que $85,7 \%$ dos respondentes estão trabalhando. Observa-se que $12,9 \%$ dos respondentes estão desempregados. Os demais respondentes nunca trabalharam ou estagiaram.

Tabela 5 - Formação

\begin{tabular}{lcc}
\hline Variáveis & Frequência & Percentual \\
\hline Cursos de & 26 & 37,1 \\
Administração & 7 & 10 \\
Gestão Ambiental & 16 & 22,9 \\
Gestão Empresarial & 1 & 1,4 \\
Logística & 2 & 2,9 \\
Pedagogia & 18 & 25,7 \\
Recursos Humanos & $\mathbf{7 0}$ & $\mathbf{1 0 0 \%}$ \\
\hline Total & &
\end{tabular}

Fonte: Dados da pesquisa (2017). 
$\mathrm{Na}$ análise dos dados sobre a Formação, o curso de Administração correspondeu a $37,1 \%$ dos respondentes, seguido de estudantes do curso Superior em Tecnologia em Recursos Humanos com $25,7 \%$ dos respondentes.

Tabela 6 - Área de atuação

\begin{tabular}{lcc}
\hline Variáveis & Frequência & Percentual \\
\hline Cargo de & & \\
Sócio/ Presidente/ Diretor & 4 & 5,7 \\
Gerente/Chefia/Coordenação & 3 & 4,3 \\
Analista /Técnicos & 4 & 5,7 \\
Assistente/Auxiliar & 25 & 35,7 \\
Operacionais & & 48,6 \\
/Administrativos & 34 & $\mathbf{1 0 0 \%}$ \\
\hline Total & $\mathbf{7 0}$ & \\
\hline
\end{tabular}

Fonte: Dados da pesquisa (2017).

Em relação à área de atuação o maior número de respondentes concentra-se no grupo de operacionais e administrativos com 48,6\%, seguido por assistente e auxiliar com $35,7 \%$. Os demais respondentes são analistas, técnicos e cargos de chefia. 


\subsection{Apresentação da análise descritiva}

Tabela 7 - Rotina de Trabalho

\begin{tabular}{|c|c|c|c|c|c|c|c|c|c|}
\hline \multicolumn{2}{|l|}{ Itens } & DT & DP & D & $\mathbf{N}$ & C & $\mathrm{CP}$ & CT & Total \\
\hline \multirow{2}{*}{$\begin{array}{l}\text { 1) Gosto de trabalhar } \\
\text { em um ambiente } \\
\text { animador. }\end{array}$} & $\mathbf{N}$ & 3 & 0 & 0 & 0 & 22 & 4 & 41 & 70 \\
\hline & $\%$ & 4,3 & 0 & 0 & 0 & 31,4 & 5,7 & 58,6 & $100 \%$ \\
\hline \multirow{2}{*}{$\begin{array}{l}\text { 2) Acho Importante } \\
\text { trabalhar em uma } \\
\text { empresa que pensa } \\
\text { para frente, aplica } \\
\text { novas práticas de } \\
\text { trabalho. }\end{array}$} & $\mathbf{N}$ & 3 & 0 & 0 & 0 & 17 & 3 & 47 & 70 \\
\hline & $\%$ & 4,3 & 0 & 0 & 0 & 24,3 & 4,3 & 67,1 & $100 \%$ \\
\hline \multirow{2}{*}{$\begin{array}{l}\text { 3) Prefiro trabalhar } \\
\text { em empresas que } \\
\text { valorizam e utilizam a } \\
\text { criatividade. }\end{array}$} & $\mathbf{N}$ & 3 & 0 & 0 & 0 & 19 & 9 & 39 & 70 \\
\hline & $\%$ & 4,3 & 0 & 0 & 0 & 27,1 & 12,9 & 55,7 & $100 \%$ \\
\hline \multirow{2}{*}{$\begin{array}{l}\text { 4) Acho importante } \\
\text { trabalhar em empresa } \\
\text { que tenha } \\
\text { produtos/serviços de } \\
\text { qualidade. }\end{array}$} & $\mathbf{N}$ & 3 & 0 & 0 & 0 & 20 & 2 & 45 & 70 \\
\hline & $\%$ & 4,3 & 0 & 0 & 0 & 28,6 & 2,9 & 64,3 & $100 \%$ \\
\hline \multirow{2}{*}{$\begin{array}{l}\text { 5) Acho importante } \\
\text { trabalhar em uma } \\
\text { empresa que tenha } \\
\text { produtos/serviços } \\
\text { inovadores. }\end{array}$} & $\mathbf{N}$ & 0 & 1 & 0 & 2 & 21 & 12 & 34 & 70 \\
\hline & $\%$ & 0 & 1,4 & 0 & 2,9 & 30,0 & 17,1 & 48,6 & $100 \%$ \\
\hline
\end{tabular}

Fonte: Dados da pesquisa (2017).

Legenda: discordo totalmente (DT); discordo parcialmente (DP); discordo (D); neutro (N); concordo (C); concordo parcialmente (CP); concordo totalmente (CT).

A análise detalhada do fator "Rotina de Trabalho" retrata que a assertiva 2 "Acho importante trabalhar em uma empresa que pensa para frente, aplica novas práticas de trabalho" teve o maior índice de concordância entre as respostas. Adami (2014) relata que esta geração está vivendo muitas mudanças e a inovação faz parte da sua rotina, pois querem respostas imediatas, satisfação instantânea e novidades o tempo todo, apreciando a diversidade e aceitando desafios, portanto, os achados da pesquisa corroboram com as ideias apresentadas pela autora.

Para uma geração tecnologicamente integrada, a inovação é o aspecto mais relevante, proporcionando liberdade de criação e novas práticas de trabalho. 
Tabela 8 -Interação Pessoal

\begin{tabular}{|c|c|c|c|c|c|c|c|c|c|}
\hline \multicolumn{2}{|l|}{ Itens } & DT & DP & D & $\mathbf{N}$ & $\mathbf{C}$ & $\mathbf{C P}$ & CT & Total \\
\hline \multirow{2}{*}{$\begin{array}{l}\text { 6) Prefiro } \\
\text { trabalhar em } \\
\text { ambiente de } \\
\text { trabalho divertidos. }\end{array}$} & $\mathbf{N}$ & 1 & 0 & 0 & 0 & 18 & 20 & 31 & 70 \\
\hline & $\%$ & 1,4 & 0 & 0 & 0 & 25,7 & 28,6 & 44,3 & $100 \%$ \\
\hline \multirow{2}{*}{$\begin{array}{l}\text { 7) Acho } \\
\text { importante ter um } \\
\text { bom } \\
\text { relacionamento } \\
\text { com meus } \\
\text { superiores. }\end{array}$} & $\mathbf{N}$ & 0 & 1 & 0 & 1 & 16 & 11 & 41 & 70 \\
\hline & $\%$ & 0 & 1,4 & 0 & 1,4 & 22,9 & 15,7 & 58,6 & $100 \%$ \\
\hline \multirow{2}{*}{$\begin{array}{l}\text { 8) Acho } \\
\text { importante ter um } \\
\text { bom } \\
\text { relacionamento } \\
\text { com meus colegas. }\end{array}$} & $\mathbf{N}$ & 2 & 0 & 0 & 0 & 21 & 6 & 41 & 70 \\
\hline & $\%$ & 2,9 & 0 & 0 & 0 & 30,0 & 8,6 & 58,6 & $100 \%$ \\
\hline \multirow{2}{*}{$\begin{array}{l}\text { 9) Prefiro } \\
\text { trabalhar onde } \\
\text { tenho colegas } \\
\text { que me apoiam e } \\
\text { encorajam. }\end{array}$} & $\mathbf{N}$ & 1 & 1 & 0 & 0 & 23 & 9 & 36 & 70 \\
\hline & $\%$ & $1,4 \%$ & 1,4 & 0 & 0 & 32,9 & 12,9 & 51,4 & $100 \%$ \\
\hline \multirow{2}{*}{$\begin{array}{l}\text { 10) Gosto de } \\
\text { trabalhar em } \\
\text { ambientes de } \\
\text { trabalho felizes. }\end{array}$} & $\mathbf{N}$ & 0 & 1 & 0 & 0 & 21 & 5 & 43 & 70 \\
\hline & $\%$ & 0 & 1,4 & 0 & 0 & 30,0 & 7,1 & 61,4 & $100 \%$ \\
\hline
\end{tabular}

Fonte: Dados da pesquisa (2017).

Legenda: discordo totalmente (DT); discordo parcialmente (DP); discordo (D); neutro (N); concordo (C); concordo parcialmente (CP); concordo totalmente (CT).

A análise detalhada do fator "Interação Pessoal" retrata quenas assertivas 7 e 8 os respondentes acham importante ter bom relacionamento com os superiores e colegas de trabalho. De acordo com Robbins, Judge e Sobral (2010, p. 141) os valores na força de trabalho para a geração Y são "autoconfiança, sucesso financeiro, independência pessoal, junto com trabalho de equipe, lealdade a si mesmos e aos relacionamentos".

A assertiva 10 "Gosto de trabalhar em ambientes de trabalho felizes" teve a maior concordância, indicando que preferem trabalhar onde se sintam bem, mantendo bom clima organizacional. 
Tabela 9 -Benefícios Econômicos

\begin{tabular}{|c|c|c|c|c|c|c|c|c|c|}
\hline \multicolumn{2}{|l|}{ Itens } & DT & DP & D & $\mathbf{N}$ & $\mathbf{C}$ & $\mathrm{CP}$ & CT & Total \\
\hline \multirow{2}{*}{$\begin{array}{l}\text { 11) Prefiro trabalhar } \\
\text { em empresas que } \\
\text { proporcionam boas } \\
\text { oportunidades de } \\
\text { promoção e } \\
\text { crescimento. }\end{array}$} & $\mathbf{N}$ & 0 & 0 & 0 & 1 & 18 & 5 & 46 & 70 \\
\hline & $\%$ & 0 & 0 & 0 & 1,4 & 25,7 & 7,1 & 65,7 & $100 \%$ \\
\hline \multirow{2}{*}{$\begin{array}{l}\text { 12) Prefiro trabalhar } \\
\text { em uma instituição } \\
\text { que me dá } \\
\text { estabilidade de } \\
\text { emprego. }\end{array}$} & $\mathbf{N}$ & 0 & 1 & 0 & 1 & 24 & 8 & 36 & 70 \\
\hline & $\%$ & 0 & 1,4 & 0 & 1,4 & 34,6 & 11,4 & 51,4 & $100 \%$ \\
\hline \multirow{2}{*}{$\begin{array}{l}\text { 13)Acho importante } \\
\text { trabalhar em uma } \\
\text { empresa onde posso } \\
\text { ter experiências } \\
\text { práticas, interagindo } \\
\text { com outros } \\
\text { departamentos }\end{array}$} & $\mathbf{N}$ & 0 & 1 & 0 & 2 & 19 & 7 & 41 & 70 \\
\hline & $\%$ & 0 & 1,4 & 0 & 2,9 & 27,1 & 10,0 & 58,6 & $100 \%$ \\
\hline \multirow{2}{*}{$\begin{array}{l}\text { 14) Acho importante } \\
\text { trabalhar em local que } \\
\text { proporciona salários } \\
\text { acima da média. }\end{array}$} & $\mathbf{N}$ & 0 & 0 & 0 & 1 & 21 & 8 & 40 & 70 \\
\hline & $\%$ & 0 & 0 & 0 & 1,4 & 30,0 & 11,4 & 57,1 & $100 \%$ \\
\hline \multirow{2}{*}{$\begin{array}{l}\text { 15) Prefiro trabalhar } \\
\text { em locais com bons } \\
\text { benefícios extra } \\
\text { salariais. }\end{array}$} & $\mathbf{N}$ & 0 & 1 & 0 & 1 & 22 & 8 & 38 & 70 \\
\hline & $\%$ & 0 & 1,4 & 0 & 1,4 & 31,4 & 11,4 & 54,3 & $100 \%$ \\
\hline
\end{tabular}

Fonte: Dados da pesquisa (2017).

Legenda: discordo totalmente (DT); discordo parcialmente (DP); discordo (D); neutro (N); concordo (C); concordo parcialmente (CP); concordo totalmente (CT).

A análise detalhada do fator "Benefícios Econômicos" retrata que a assertiva número 11 "Prefiro trabalhar em empresas que proporcionam boas oportunidades de promoção e crescimento" teve o maior índice de concordância entre as respostas e querem ser reconhecidos pelo que fazem. Calliari e Motta (2012) relatam que benefícios, recompensas e outras maneiras de premiar suas atuações são muito bem-vindas e apreciadas. 
Tabela 10 - Desenvolvimento Profissional

\begin{tabular}{|c|c|c|c|c|c|c|c|c|c|}
\hline \multicolumn{2}{|l|}{ Itens } & DT & DP & D & $\mathbf{N}$ & $\mathbf{C}$ & $\mathrm{CP}$ & CT & Total \\
\hline \multirow{2}{*}{$\begin{array}{l}\text { 16) Gosto que meu } \\
\text { trabalho seja } \\
\text { reconhecido pela } \\
\text { gestão }\end{array}$} & $\mathbf{N}$ & 0 & 0 & 0 & 1 & 20 & 7 & 42 & 70 \\
\hline & $\%$ & 0 & 0 & 0 & 1,4 & 28,6 & 10,0 & 60,0 & $100 \%$ \\
\hline \multirow{2}{*}{$\begin{array}{l}\text { 17) Acho importante } \\
\text { trabalhar em um local } \\
\text { que me proporcionará } \\
\text { oportunidades de } \\
\text { futuros empregos } \\
\text { melhores. }\end{array}$} & $\mathbf{N}$ & 0 & 0 & 0 & 0 & 20 & 4 & 46 & 70 \\
\hline & $\%$ & 0 & 0 & 0 & 0 & 28,6 & 5,7 & 65,7 & $100 \%$ \\
\hline \multirow{2}{*}{$\begin{array}{l}\text { 18) É importante } \\
\text { sentir-me bem ao } \\
\text { trabalhar para empresa } \\
\text { onde trabalho. }\end{array}$} & $\mathbf{N}$ & 0 & 0 & 0 & 0 & 23 & 5 & 42 & 70 \\
\hline & $\%$ & 0 & 0 & 0 & 0 & 32,9 & 7,1 & 60,0 & $100 \%$ \\
\hline \multirow{2}{*}{$\begin{array}{l}\text { 19) Prefiro trabalhar } \\
\text { em empresas que me } \\
\text { fazem sentir mais } \\
\text { autoconfiante por } \\
\text { trabalhar nelas.. }\end{array}$} & $\mathbf{N}$ & 0 & 1 & 0 & 1 & 21 & 4 & 43 & 70 \\
\hline & $\%$ & 0 & 1,4 & 0 & 1,4 & 30,0 & 5,7 & 61,4 & $100 \%$ \\
\hline \multirow{2}{*}{$\begin{array}{l}\text { 20) Gosto de } \\
\text { trabalhar em locais } \\
\text { que me proporcionam } \\
\text { experiências } \\
\text { importantes para } \\
\text { minha carreira. }\end{array}$} & $\mathbf{N}$ & 0 & 0 & 0 & 0 & 24 & 6 & 40 & 70 \\
\hline & $\%$ & 0 & 0 & 0 & 0 & 34,3 & 8,6 & 57,1 & $100 \%$ \\
\hline
\end{tabular}

Fonte: Dados da pesquisa (2017).

Legenda: discordo totalmente (DT); discordo parcialmente (DP); discordo (D); neutro (N); concordo (C); concordo parcialmente $(\mathrm{CP})$; concordo totalmente $(\mathrm{CT})$.

A análise detalhada do fator "Desenvolvimento Profissional" retrata que a assertiva número 17 “Acho importante trabalhar em um local que me proporcionará oportunidades de futuros empregos melhores" teve o maior índice de concordância entre as respostas. Oliveira (2011, p. 38) relata que para esses jovens 'seu supremo reconhecimento, não acontecerá por uma carreira profissional, mas por sua carreira de vida." Desta forma, enfatiza o alinhamento profissional em busca de um emprego melhor com experiências para sua carreira, e o seu bemestar. 
Tabela 11 - Responsabilidade Social

\begin{tabular}{|c|c|c|c|c|c|c|c|c|c|}
\hline \multicolumn{2}{|l|}{ Itens } & DT & DP & D & $\mathbf{N}$ & $\mathbf{C}$ & $\mathbf{C P}$ & CT & Total \\
\hline \multirow{2}{*}{$\begin{array}{l}\text { 21) Acho importante } \\
\text { trabalhar em uma } \\
\text { empresa humanitária, } \\
\text { que faz bem à } \\
\text { sociedade. }\end{array}$} & $\mathbf{N}$ & 1 & 0 & 0 & 1 & 20 & 8 & 41 & 70 \\
\hline & $\%$ & 1,4 & 0 & 0 & 0 & 28,6 & 11,4 & 58,6 & $100 \%$ \\
\hline \multirow{2}{*}{$\begin{array}{l}\text { 22) Prefiro trabalhar } \\
\text { em um local onde } \\
\text { posso aplicar o } \\
\text { conhecimento que } \\
\text { adquiri em outras } \\
\text { instituições. }\end{array}$} & $\mathbf{N}$ & 0 & 1 & 1 & 1 & 21 & 10 & 36 & 70 \\
\hline & $\%$ & 0 & 1,4 & 1,4 & 1,4 & 30,0 & 14,3 & 51,4 & $100 \%$ \\
\hline \multirow{2}{*}{$\begin{array}{l}\text { 23) Gosto de trabalhar } \\
\text { em locais onde posso } \\
\text { ensinar aos outros } \\
\text { aquilo que aprendi. }\end{array}$} & $\mathbf{N}$ & 0 & 1 & 2 & 0 & 24 & 7 & 36 & 70 \\
\hline & $\%$ & 0 & 1,4 & 2,9 & 0 & 34,3 & 10,0 & 51,4 & $100 \%$ \\
\hline \multirow{2}{*}{$\begin{array}{l}\text { 24) Acho importante } \\
\text { trabalhar em um local } \\
\text { onde me sinto } \\
\text { aceito(a), parte da } \\
\text { instituição. }\end{array}$} & $\mathbf{N}$ & 0 & 0 & 0 & 0 & 24 & 4 & 42 & 70 \\
\hline & $\%$ & 0 & 0 & 0 & 0 & 34,3 & 5,7 & 60,0 & $100 \%$ \\
\hline \multirow{2}{*}{$\begin{array}{l}\text { 25) Gosto de } \\
\text { trabalhar em empresas } \\
\text { que são voltadas ao } \\
\text { cliente. }\end{array}$} & $\mathbf{N}$ & 1 & 1 & 0 & 1 & 26 & 18 & 23 & 70 \\
\hline & $\%$ & 1,4 & 1,4 & 0 & 1,4 & 37,1 & 25,7 & 32,9 & $100 \%$ \\
\hline
\end{tabular}

Fonte: Dados da pesquisa (2017).

Legenda: discordo totalmente (DT); discordo parcialmente (DP); discordo (D); neutro (N); concordo $(\mathrm{C})$; concordo parcialmente $(\mathrm{CP})$; concordo totalmente $(\mathrm{CT})$.

A análise detalhada do fator "Responsabilidade Social" retrata que a assertiva número 24 "Acho importante trabalhar em um local onde me sinto aceito (a), parte da instituição" teve o maior índice de concordância entre as respostas denotando que sentir-se parte da organização e do grupo no qual faz parte é valorizado pela Geração Y.

A maioria dos respondentes concentrou suas respostas em concordo totalmente considerando muito importante trabalhar em uma empresa envolvida em ações comunitárias; com abertura para que o funcionário possa colocar em práticas o conhecimento adquirido com outras experiências profissionais trocando experiências e ensinando outros colegas.De acordo com Adami (2014, p.51) "a geração Y busca nas organizações aquilo que ele valoriza, ou seja, organizações que se preocupem com filantropia, sustentabilidade e com trabalhos voluntários".

Em relação aos clientes, a assertiva 25, os respondentes apenas concordam ao expressar a sua preferência em empresas que são voltadas para o cliente. 


\section{CONSIDERAÇÕES FINAIS}

Percebe-se que a Geração Y representa uma nova força de trabalho diferente das gerações anteriores na sua percepção de emprego ideal, tornando um desafio para as empresasse adequarem as mudanças e propiciarem fatores que deem significado e perspectiva ao seu trabalho, bem como a qualidade de vida.

O estudo se concentrou em responder a seguinte pergunta: Qual a percepção da Geração Y sobre o emprego ideal? Os resultados permitiram verificar que a Geração Y em sua maioria busca trabalhar em empresas que proporcione oportunidade de crescimento profissional com valorização e reconhecimento do seu trabalho, em um ambiente animador, criativo com bom relacionamento com seus superiores e colegas.

Desta forma, assume-se como aceita a segunda hipótese: a Geração Y considera importante os relacionamentos interpessoais estabelecidos com as chefias e colegas.

Considerando suas características, essa geração procura trabalhar em empresas que tenham o mesmo perfil que o seu, assim, observada na pesquisa: empresas criativas, inovadoras e que pense para frente.

Sua carreira não é relacionada com a sua permanência na empresa, uma vez que buscam o significado de seu trabalho conciliado com sua vida pessoal, no entanto as empresas precisam compreender seu comportamento e identificar o que valorizam, para que possam proporcionar diferenciais para atraí-los e retê-los.

Contudo, é preciso gerir a diversidade considerando o novo cenário corporativo multigeracional. Faz-se necessário inovar, estimular a criatividade, a troca de conhecimento, manter um bom clima organizacional, proporcionar oportunidades de ascensão, reconhecimento e bem-estar. A conciliação da vida profissional com interesses pessoais garantem a qualidade de vida, nessa percepção de emprego ideal para a Geração Y, trazendo uma perspectiva mais humanitária, que torna-se primordial tanto para ela quanto para a própria organização.

\section{REFERÊNCIAS}

ADAMI, Elisabete (Org.). Gestão de talentos. São Paulo: Pearson Education do Brasil, 2014. (Coleção Bibliografia Universitária Pearson). 
BERTHON, P.; EWING, M.; HAH, L. Captivating company: Dimensions of attractiveness in employer branding. International Journal of Advertising, v. 24, n. 2, 2005.

CALLIARI, Marcos; MOTTA, Alfredo. Código Y: Decifrando a geração que está mudando o país. São Paulo: Évora, 2012.

DESSLER, Gary. Administração de recursos humanos. 3. ed. São Paulo: Pearson Education do Brasil, 2014.

GIL, Antonio Carlos. Métodos e técnicas de pesquisa social. 6.ed. São Paulo: Atlas, 2008.

MASCARENHAS, Sidnei Augusto. Metodologia científica . São Paulo: Education do Brasil, 2012.

OLIVEIRA,Sidnei.Geração Y:Ser potencial ou ser talento?Faça por merecer. 3. ed. São Paulo: Integrare Editora, 2011.

Editora, 2011.

Jovens para sempre:Como entender os conflitos de gerações. São Paulo: Integrare

ORSI, Ademar. Remuneração de pessoas nas organizações.Curitiba: InterSaberes, 2015.

ROBBINS, P. Stephen. Fundamentos do comportamento organizacional. 8. ed. São Paulo: Pearson Prentice Hall, 2009.

ROBBINS, P. Stephen; JUDGE, A. Timothy; SOBRAL, Felipe.Comportamento organizacional.14. ed. São Paulo: Pearson Prentice Hall, 2010.

SEVERINO, Antonio Joaquim. Metodologia do trabalho científico. 23. ed. rev. e atual. São Paulo: Cortez, 2007. 